\title{
IPTU PARTICIPATIVO E INTERNET PARA OS CIDADÃOS: PROJETO DE CIDADE DIGITAL DE ENGENHEIRO BELTRÃO - PARANÁ, BRASIL
}

\section{PARTICIPATORY IPTU AND INTERNET FOR CITIZENS: DIGITAL CITY DESIGN OF ENGENHEIRO BELTRÃO - PARANÁ, BRAZIL}

\author{
Danieli Aparecida From \\ Pontifícia Universidade Católica do Paraná - PUCPR \\ arquivopr@gmail.com \\ Carla Cavichiolo Flores \\ Pontifícia Universidade Católica do Paraná - PUCPR \\ $\underline{\text { carla@ copta.com.br }}$ \\ Denis Alcides Rezende \\ Pontifícia Universidade Católica do Paraná - PUCPR \\ denis.rezende@pucpr.br
}

Submissão: $10 / 09 / 2020$

Aprovação: 27/04/2021

\section{RESUMO}

Conscientizar o cidadão quanto à importância do pagamento de impostos e envolvê-lo no processo de decisão quanto aos investimentos que considera prioritários na sua cidade não se demonstra tarefa fácil. Poucos municípios brasileiros conseguem utilizar de maneira adequada os instrumentos de gestão que têm disponíveis, e neste viés, o Imposto Predial e Territorial Urbano (IPTU) se constitui uma das principais fontes de arrecadação tendo uma função social, principalmente, quando se trata de uma adequada política de desenvolvimento urbano. O objetivo é analisar o projeto de "cidade digital", intitulado EBOnline, de Engenheiro Beltrão, no Estado do Paraná e a contribuição do IPTU participativo para a existência do projeto. A metodologia da pesquisa enfatiza um estudo de caso. Os resultados auferidos demonstram que é possível aplicar os recursos orçamentários de acordo com a opinião da população, pois o dinheiro arrecadado com o IPTU foi revertido em sinal de internet, gratuita, para os cidadãos, possibilitando à cidade ser reconhecida como digital. A conclusão traz que a participação popular, como um método inovador de se fazer a gestão urbana, pode ser uma realidade desde que se desenhem estratégias capazes de aumentar e incentivar a participação social, assim como propiciar o atendimento ao anseio dos cidadãos, contribuindo assim com a melhoria da qualidade de vida daqueles que habitam as cidades, como foi o caso do projeto de cidade digital de Engenheiro Beltrão.

Palavras-chave: Cidade Digital. Imposto Predial e Territorial Urbano. Orçamento Participativo. EBOnline. IPTU Participativo. 


\begin{abstract}
Making citizens aware of the importance of paying taxes and involving them in the decisionmaking process regarding the investments they consider to be a priority in their city is no easy task. Few Brazilian municipalities are able to make adequate use of the management instruments they have available, and in this regard, the Urban Property Tax (IPTU) is one of the main sources of revenue having a social function, especially when it becomes an adequate urban development policy. The objective is to analyze the "digital city" project in Engenheiro Beltrão, state of Paraná, entitled EBOnline, and the contribution of the participatory property tax to the existence of the project. The research methodology emphasizes a case study. The results show that it is possible to apply budget resources according to the opinion of the population. The money collected with the IPTU was reverted in free internet signal to citizens, enabling the city to be recognized as digital. The conclusion is that popular participation as an innovative method of urban management can be a reality, provided that strategies are designed to increase and encourage social participation, and the desires of citizens are met, thus contributing to the improvement of the quality of life of those who inhabit the cities, as was the case of the Engenheiro Beltrão digital city project.
\end{abstract}

Keywords: Digital City. Urban Land and Territorial Tax. Participatory Budgeting. EBOnline. Participative IPTU.

\title{
1. INTRODUÇÃO
}

As cidades tidas como digitais estão em evidência desde o final da década de 1990 quando a tecnologia da informação começou a ganhar destaque devido à popularização e acesso à internet. Surgiu aí uma oportunidade de modernização e diminuição da distância entre o poder público e o cidadão, ao se oferecer informações e serviços que, até então, só poderiam ser disponibilizados de maneira física. Assim sendo, planejar o investimento em tecnologia da informação, incluindo o governo eletrônico e os recursos tecnológicos, pode ser um instrumento complementar para uma gestão competente das cidades, o que aliado à participação popular e destinação adequada dos recursos públicos garante maior efetividade à gestão pública (GUERREIRO, 2006; REZENDE, 2012; 2018; REZENDE; RIBEIRO, 2018).

O destaque dos serviços públicos oferecidos digitalmente suscita uma necessidade de incluir os cidadãos nos projetos de cidade digital para entender seus anseios, o que é possível num orçamento público participativo. Desde o final da década de 1970 ouve-se falar em orçamento participativo no Brasil, sendo a experiência de maior repercussão a de Porto Alegre, no Estado do Rio Grande do Sul, a qual ainda em 1989 permitiu aos cidadãos a participação na gestão da cidade após a implantação dos Conselhos Populares (MINGHELLI, 2005; FARIA, 2010).

Quanto aos problemas da pesquisa, não basta oferecer internet aos cidadãos, é preciso baratear os custos de aquisição e manutenção de computadores e o próprio acesso à internet deve ser facilitado, por meio de pontos de acesso públicos e capacitação digital para quem precisa. Porém, as facilidades que os recursos da tecnologia da informação trazem, por si só, não garantem as melhores condições para a população, é preciso ir além da inclusão digital, pois o setor público é o local onde as novas tecnologias estão menos desenvolvidas, assim os obstáculos à inovação são maiores, sendo preciso incluir uma "e-governança", que inclua a participação dos cidadãos na tomada de decisões políticas (FERREIRA, 2003; CASTELLS et $a l .$, 2005; SANTOS; BERNARDES; ROVER, 2012; MACEDO; VALADARES, 2020). . 
Apresentado o Imposto Predial e Territorial Urbano (IPTU) como uma das principais fontes de arrecadação municipal e, em se tratando de uma política adequada de desenvolvimento urbano, é mal fiscalizado, falta preparo técnico dos servidores públicos e os municípios acabam arrecadando pouco. Sem contar que as prefeituras evitam reajustes, principalmente em ano eleitoral e, muitas vezes, não existem políticas de incentivo para o pagamento, o que não traz garantias reais à população de onde e como será investido esse recurso (TARAPANOFF, 2004; GOMES, 2005; GUERREIRO, 2006; DALLARI, 2010).

A questão-problema da pesquisa é: Engenheiro Beltrão tem um projeto de cidade digital possibilitado pelo IPTU participativo?

O objetivo é analisar o IPTU participativo e a internet para os cidadãos do projeto de cidade digital de Engenheiro Beltrão.

Portanto, justifica-se a pesquisa ao perceber que Engenheiro Beltrão tem adotado medidas previstas no orçamento participativo ao incluir seus cidadãos realizando consultas públicas e incentivando o exercício da cidadania para disponibilizar sinal gratuito de internet se utilizando de um instrumento de arrecadação municipal, o IPTU. Isso demonstra a preocupação da gestão urbana em organizar políticas públicas de inclusão social que viabilizem o acesso ao cotidiano de uma sociedade em rede, uma vez que conscientiza e envolve os cidadãos no processo do planejamento orçamentário municipal. Ainda, o IPTU serve para cobrir qualquer espécie de gastos da gestão pública, o que permite afirmar que alternativas de fortalecimento do poder arrecadatório desse tributo trará benefícios à sociedade, a qual por meio da participação popular compreenderá a importância do seu envolvimento no orçamento do município (PIRES, 2001; SILVEIRA, 2002).

Assim, a conscientização da população, para que esta tenha noções de planejamento e de políticas públicas se faz relevante, pois evita manipulações políticas, visto que a elaboração e execução do orçamento participativo é uma tarefa que exige cuidados e transparência (TURBAN; MEREDITH, 1994; OLIVEIRA, 2002).

Dessa maneira, este instrumento de gestão participativa, o IPTU, a cidade digital e como esta foi possibilitada em Engenheiro Beltrão, as ferramentas utilizadas, custos, alcance, tempo e qualidade do serviço oferecidos no município pesquisado e por meio da participação popular é de suma importância, pois permitiu o direcionamento financeiro de uma política urbana, assim como o planejamento do que fazer com o recurso advindo deste imposto (SUNDFELD, 2010).

Por fim, o desafio de Engenheiro Beltrão foi fazer com que a cidade fosse reconhecida como digital incentivando a participação dos munícipes quanto aos investimentos provenientes da arrecadação municipal do tributo IPTU e destinação destes recursos para um anseio popular: disponibilização de sinal de internet gratuita para todos os cidadãos.

\section{REVISÃO DE LITERATURA}

\subsection{Imposto Predial e Territorial Urbano (IPTU) e Orçamento Participativo}

Dallari (2010) traz que o Imposto Predial e Territorial Urbano (IPTU) é considerado o principal tributo de um município estando vinculado ao desenvolvimento, planejamento urbano e crescimento da cidade e deveria servir como instrumento de uso racional da ocupação do solo e adensamento populacional, previsto no Estatuto da Cidade (Lei 10.257/2001), em seu art. $4^{\circ}$, IV, a, que define o IPTU como instrumento de política urbana.

O Imposto sobre a Propriedade Predial e Territorial Urbano é tipicamente fiscal, seu objetivo principal, e quase que único, é a obtenção de recursos financeiros para os municípios e deve promover o desenvolvimento do município, no qual a propriedade particular deve 
contribuir direta ou indiretamente para o benefício da coletividade (MACHADO, 2009; LASMAR, 2012).

Essa notoriedade de forte instrumento de política urbana teve maior destaque após a Emenda Constitucional 29, a qual trouxe novas redações aos incisos do parágrafo primeiro, do artigo 156, da Constituição Federal, pois se de um lado o IPTU serve como instrumento para que a propriedade seja utilizada de acordo com sua função social, e não subutilizada ou utilizada, em descompasso com este princípio, e deve adequar-se à capacidade contributiva do dono da propriedade. Porém, o que se vê na prática é o oposto, onde inconsistências de cadastros imobiliários, modelos de aferição ultrapassados e informação quanto à capacidade contributiva defasada trazem um cenário em que a maioria dos municípios arrecada pouco com o IPTU (FERREIRA, 2003).

Em 2013, foi publicado pela Frente Nacional de Prefeitos (FNP), referente ao ano de 2012, um estudo sobre a baixa arrecadação do IPTU, o qual revelou que em sendo um tributo de arrecadação direta, e de alta visibilidade por parte do contribuinte, sempre gera muitas polêmicas, o que acaba fazendo com que as prefeituras evitem reajustes acima dos índices de inflação, principalmente em anos de pleito eleitoral para evitar desgaste político, o que dificulta políticas redistributivas e de revisão de valores de taxação de impostos, o que tem sido bastante discutido. Nesse limiar de baixa arrecadação, os municípios menores são os que mais sofrem, em especial aqueles com menos de 20 mil habitantes, nos quais a participação do IPTU na receita corrente é de menos de 1\%, enquanto nos municípios com mais de 500 mil habitantes é de 9,6\% (DOWNS, 1957; HIBBS JR, 1977; ALESINA; ROSENTHAL, 1995; WITTMAN, 1995; SCHMIDT, 1996; CASTLES; OBINGER, 2007; LARCINESE, 2007; LIMA; FERNANDES, 2014).

Esse tributo, no Brasil, é taxado abaixo da média dos países da Organização para a Cooperação e o Desenvolvimento Econômico (OCDE), enquanto carga tributária e representatividade junto ao Produto Interno Bruto (PIB), pois se nos países da OCDE a arrecadação se concentra em torno de $35 \%$ do PIB, aqui gira em torno de 33,7\%, segundo dados da Receita Federal, base 2014 (PAES; BUGARIN, 2006; LIMA; FERNANDES, 2014).

Guedes (2001) afirma que a política fiscal é quem determina o processo de planejamento, sendo condição mais que necessária para que os municípios dependam menos do governo federal e de transferências estaduais de recursos. E que os municípios deveriam aproveitar melhor essa competência para tributar, definir taxas, isenções, cadastros e administração desses impostos que são de exclusividade municipal, tais como o IPTU, o ITBI e o ISS.

Na questão fiscal, observa-se a Lei Complementar $n^{\circ} 101$, de 04 de maio de 2000, mais conhecida como Lei de Responsabilidade Fiscal (LRF), a qual estabelece regras e punições, em caso de descumprimento, para as finanças públicas voltadas à responsabilidade com o dinheiro público e trouxe desafios aos gestores públicos brasileiros ao exigir planejamento, limitação e transparência dos gastos, acompanhamento sistemático, controle e participação da sociedade na definição de políticas de interesse coletivo (KHAIR, 2001; NUNES, 2002; OLIVEIRA, 2002; SOUZA, 2004).

Para a efetividade da participação popular prevista na LRF é necessário que se adotem as medidas previstas no orçamento participativo, onde os envolvidos no processo vão percebendo a real importância da participação popular para que numa dinâmica quase que de troca, aprenda o que é o orçamento do seu município e que os recursos nem sempre atenderão a todas as demandas e, assim, será preciso negociar, mas que, acima de tudo, é preciso participar (PIRES, 2001).

O orçamento participativo é uma política participativa de nível local que pensa na distribuição justa dos recursos da cidade de acordo com a opinião daqueles que lá habitam, é formado por uma etapa de participação direta dos interessados e outra etapa em que tal 
participação pode se dar por intermédio da realização de assembleias temáticas (FEDOZZI, 2007; AVRITZER, 2009a).

A implantação desse modelo de gestão de recursos públicos surgiu após a promulgação da Constituição Federal de 1988 e estimula a participação popular na definição das políticas públicas, tendo como objetivo principal aprofundar a democracia e permitir à sociedade, que antes dependia das decisões do governo, que defina suas prioridades na aplicação dos recursos públicos (VENÂNCIO, 2012).

Porém, trabalhar um orçamento com a participação popular é um grande desafio, pois existem quatro requisitos para a criação do orçamento participativo: vontade política do partido que está no poder; densidade associativa, que corresponde ao grau de coesão e de organização da sociedade ou comunidade; elementos do desenho institucional e capacidade administrativa e financeira para implantar as propostas, visto que, na maioria das vezes, acaba se limitando à resolução de problemas de infraestrutura básica devido ao engessamento da alocação de recursos, da impessoalidade no comportamento dos gestores e do endividamento público, o que abre brechas para a exploração política (AVRITZER, 2002).

Por fim, a participação cidadã no orçamento público permite que as pessoas entendam mais de política, de suas próprias necessidades, das necessidades da comunidade e do exercício de seus direitos e resulta na crença de que ela participando o resultado será garantido (SOUZA et al., 2019).

\subsection{Cidade Digital}

Uma cidade digital deve fornecer serviços e informações, por meio dos recursos de tecnologia da informação, assim como planejar e gerir esse espaço urbano conhecido como cidade, sendo possível afirmar que as primeiras referências, em se tratando de cidades digitais, remetem a experiências muito recentes em comparação à história de origem das cidades. Um documento intitulado "A Nova Carta de Atenas", de 2003, sendo uma atualização do documento original de 1933, traz em um dos seus 10 princípios que a "Cidade Inovadora" do século XXI deve permitir aos cidadãos o acesso aos serviços e informações públicas, por meio dos recursos de tecnologia da informação e comunicação (AZEVEDO, 2012; REZENDE, 2012; 2018).

Lemos (2004) afirma que após as décadas de 1970 e 1980, com a disseminação da tecnologia e a chamada sociedade da informação, é que emergiram as primeiras cidades digitais, fator devido, principalmente, à popularização e acesso à internet. Esse aumento no acesso também possibilitou, ao cidadão, cobrar que a administração pública disponibilizasse serviços de maneira virtual. Surgiu aí a oportunidade de modernização e diminuição da distância entre o poder público e o cidadão, ao oferecer informações e serviços de maneira eletrônica, o que de maneira indireta acaba por contribuir com a melhoria da qualidade de vida dos cidadãos.

Cidades digitais são portais web utilizando cidades físicas como metáfora para espaços informacionais; que podem ser vistas como uma infraestrutura de informação social local e sobre a cidade "real", que ultrapassa o entendimento da transposição física para o universo virtual e, significa, essencialmente, descobrir as potencialidades e facilidades que a tecnologia pode proporcionar à vida do cidadão. É aquela que facilita e melhora as relações entre cidadãos e governo, cidadãos e empresas e empresas e governo para que se conectem e tenham acesso a serviços de maneira gratuita onde quer que estejam fisicamente, pois substituir serviços físicos por eletrônicos já caracterizariam a cidade como digital (BESSELAAR; MELIS; BECKERS, 2000; GUERREIRO, 2006).

Em uma cidade digital não se evidencia a substituição da cidade real pela virtual, o foco está na ampliação do acesso dos cidadãos às atividades de inteligência coletiva e na 
habitação do ciberespaço, tal como na cidade geográfica, tornando o cidadão por inteiro. Já a cidade digital vista como estratégica ultrapassa a compreensão de fornecimento de serviços via tecnologia da informação (LÉVY; LEMOS, 2002; MOREIRA, 2014; REZENDE, 2012; REZENDE, 2018).

Diferentemente do conceito de cidade digital convencional e de cidade inteligente (ou smart city), a cidade digital estratégica, conceito criado por Rezende (2012), pode ser entendida como a aplicação dos recursos da tecnologia da informação na gestão do município e também na disponibilização de informações e de serviços aos cidadãos, a partir das estratégias da cidade. É um projeto mais abrangente que apenas oferecer internet para os cidadãos por meio de recursos convencionais de telecomunicações. Vai além de incluir digitalmente os cidadãos na rede mundial de computadores. Tem como base as estratégias da cidade para atender os objetivos das diferentes temáticas municipais (REZENDE, 2012; REZENDE, 2018).

\section{METODOLOGIA DA PESQUISA}

O método da pesquisa é um estudo de caso e as técnicas realizam análises qualitativas e quantitativas de natureza descritiva de informações extraídas de documentos da prefeitura disponibilizados no portal da transparência e no portal eletrônico com dados orçamentáriofinanceiros, leis e o projeto de cidade digital, assim como por meio de um questionário não estruturado encaminhado pelo $e$-Sic e respondido pela prefeitura por meio do Departamento da Tecnologia da Informação, oficialmente, pelo mesmo canal, com perguntas abertas e respostas livres quanto à arrecadação municipal, legislação, implantação, custos, alcance, qualidade do serviço e execução do projeto de cidade digital intitulado EBOnline (GIL, 2019; LAKATOS; MARCONI, 2017; YIN, 2015).

A amostra se deu por conveniência, pois é um dos métodos que permite ao pesquisador selecionar os elementos aos quais tem acesso e assim definir seu universo de pesquisa (GIL, 2010) e se concentrou no município de Engenheiro Beltrão, no Estado do Paraná - Brasil e a unidade de observação foram o canal oficial de entrada de pedidos de informações previstos na Lei de Acesso à Informação (LAI), o $e$-Sic, assim como o portal eletrônico e o portal da transparência da prefeitura municipal.

A pesquisa foi realizada no período de novembro de 2016 a novembro de 2018, atualizada em março de 2021.

\section{ANÁLISE E DISCUSSÃO DE RESULTADOS}

Localizado na região noroeste do Paraná, Engenheiro Beltrão foi o primeiro município da Comunidade dos Municípios da Região de Campo Mourão (ComCam) a disponibilizar o sinal gratuito de internet para a população. Sendo a principal atividade econômica da região a agropecuária, no setor industrial destaca-se o crescimento da produção e comercialização de confecções de vestuário assim como a indústria de álcool, a qual tem importante contribuição para a economia da cidade, tal como a geração de empregos (ENGENHEIRO BELTRÃO, 2018).

Segundo dados do Instituto Brasileiro de Geografia e Estatística (IBGE), Engenheiro Beltrão tem um território de $467.470 \mathrm{~km}^{2}$ e sua população foi estimada, em 2018, em 14.020 habitantes (IBGE, 2018).

Para implantar o solicitado pela população, sinal de internet gratuito, a prefeitura criou um projeto de cidade digital, o EBonline, por meio da Lei 1637/2010, o qual tem por objetivo levar o acesso à internet banda larga para o maior número possível de famílias e com sinal de 
qualidade. O projeto beneficiou 750 pessoas já em seu primeiro ano de implantação (ENGENHEIRO BELTRÃO, 2018).

Desde 2009, na contracapa do carnê do IPTU existe um espaço para que o cidadão beltronense indique em que o dinheiro arrecadado com o tributo deve ser aplicado no ano seguinte. Em 2009, 87\% dos contribuintes escolheram a internet gratuita como investimento prioritário para o ano de 2010, uma vez que foram entregues aproximadamente 4.500 carnês de IPTU, o que além de aumentar a arrecadação e diminuir o número de inadimplentes, por escolha do cidadão, parte do dinheiro que, muitas vezes, nem entrava nos cofres da prefeitura passou a ser investido em sinal de internet gratuita para a população.

De acordo com os dados extraídos do portal da transparência da prefeitura de Engenheiro Beltrão, o cidadão não só opinou como fez com que a arrecadação em 2009 saltasse mais de $71 \%$ se comparada à média dos anos anteriores e posteriores. Uma arrecadação que havia sido de pouco mais de $\mathrm{R} \$ 1.500 .000,00$ no ano de 2008 passou para $\mathrm{R} \$$ 2.715.531,55 em 2009, de acordo com a Tabela 1.

Tabela 1. Arrecadação do IPTU e aumento em 2009 devido ao orçamento participativo

\begin{tabular}{|cc|c|}
\hline \multicolumn{2}{|c|}{ Arrecadação IPTU } & Ano \\
\hline $\mathrm{R} \$$ & $1.139 .738,07$ & 2007 \\
\hline $\mathrm{R} \$$ & $1.553 .141,10$ & 2008 \\
\hline $\mathbf{R} \$$ & $\mathbf{2 . 7 1 5 . 5 3 1 , 5 5}$ & $\mathbf{2 0 0 9}$ \\
\hline $\mathrm{R} \$$ & $1.514 .148,00$ & 2010 \\
\hline $\mathrm{R} \$ \quad 1.917 .000,00$ & 2011 \\
\hline $\mathrm{R} \$ \quad 1.800 .000,00$ & 2012 \\
\hline & & $1.584 .805,34$ \\
\hline Média dos outros anos & $\mathbf{7 1 \%}$ \\
\hline Aumento 2009
\end{tabular}

Fonte: elaborado pelos autores (2021).

Para ter acesso, o cidadão precisa estar em dia com suas obrigações tributárias e ainda, conforme a Lei 1637/2010, se tiver filhos em idade escolar deve apresentar declaração de matrícula, assim como as carteiras de vacinação em dia. Para o usuário empresarial acessar o sinal, além de ter alvará precisa recolher o Imposto sobre Serviços (ISS), o cadastro é gratuito. Em ambos os casos, o usuário terá o custo particular de instalação dos equipamentos, os quais são oferecidos pelo comércio local por um valor aproximado de $\mathrm{R} \$ 450,00$.

A prefeitura investiu, em 2010, pouco mais de R\$ 100 mil reais com a instalação das torres e dispôs de apenas $\mathrm{R} \$ 5.500,00$ mensais dos cofres municipais para a manutenção do link do sinal de internet oferecido pela Companhia Paranaense de Energia Elétrica (Copel), o que representou um orçamento de aproximadamente $15 \%$ do valor arrecadado a mais com o IPTU participativo e projeto de cidade digital se comparada à arrecadação do ano anterior. Até 2013 foram cadastradas mais de 3 mil famílias no projeto, isso num município que possuía 4.258 famílias em domicílios particulares permanentes, segundo dados do IBGE de 2010.

No tocante à qualidade do serviço oferecido, a velocidade, em 2010, era de $128 \mathrm{kbps}$ e era limitada a 250 usuários. Em 2018, a potência do sinal era de 1MB para os usuários residenciais e de $3 \mathrm{MB}$ para as empresas, o que foi possibilitado devido a um novo servidor e maior capacidade do provedor junto a uma parceria com a Copel, o que garantiu mais estabilidade na velocidade e sinal de internet de maior qualidade e gerou um custo adicional aos cofres públicos, passando o custo para $\mathrm{R} \$ 6.800,00$ mensais. 
No final de 2015, o EBOnline estava com aproximadamente 1 mil usuários ativos e mais de 1.500 cadastrados, sendo que, destes, 160 eram empresariais.

Em dezembro de 2018 estavam cadastrados 1476 usuários, porém, utilizando efetivamente o sinal, diariamente, havia uma média de 900 antenas conectadas. Considerando-se três moradores por residência, o sinal gratuito de internet passa de 3 mil pessoas utilizando todos os dias. O sinal fornecido é via-rádio, com tecnologia $5 \mathrm{Ghz}$ e dois planos de internet para a população; residencial e empresarial. O plano residencial é para o Cadastro de Pessoa Física (CPF) ao qual é fornecido 1MB ao usuário e um plano empresarial, vinculado ao Cadastro Nacional de Pessoa Jurídica (CNPJ) de 3MB por empresa. A manutenção da estrutura de transmissão e link de internet é mantida pela prefeitura e o custo mensal do projeto gira em torno de $\mathrm{R} \$ 18.000,00$, o que equivale a um custo médio de $\mathrm{R} \$$ 12,00 por usuário/mês.

Cabe ressaltar que, em fevereiro de 2010, quando da implantação do Projeto, a cidade de Engenheiro Beltrão contava apenas com sinal de internet de operadoras de telefonia privadas e das seguintes prestadoras de serviços, conforme Quadro 1.

Quadro 1. Prestadoras de serviços de internet em Engenheiro Beltrão em 2010

\begin{tabular}{|c|c|}
\hline Empresa & Tipo de serviço \\
\hline \hline Oi Telecom & ADSL \\
\hline \hline TIM Sul & Modem 3G \\
\hline \hline VIVO & Modem 3G \\
\hline \hline IRapida & Via Rádio \\
\hline \hline Visão Net & Via Rádio \\
\hline
\end{tabular}

Fonte: Adaptado de Aguiar (2011).

De acordo com a prefeitura de Engenheiro Beltrão (2018), muitos munícipes já possuíam computadores em suas casas, anterior ao ano de 2009, adquiridos por meio de incentivos do Governo Federal, tais como o programa Computador para Todos. No entanto, devido aos valores ofertados pelas prestadoras de serviços de internet privadas, a maioria dos cidadãos não tinha o serviço à disposição, pois era considerado muito caro, segundo Aguiar (2011). Sem contar que, na região rural onde não chegavam as linhas fixas, nem sinal de linhas móveis, a limitação era ainda maior. Só quem tinha poder aquisitivo maior conseguia investir em acesso de internet sem fio, e quando a cobertura de sinal $3 \mathrm{G}$ era disponibilizada por alguma operadora de telefonia.

O Departamento de Tecnologia da Informação da Prefeitura de Engenheiro Beltrão também informou que as empresas privadas prestadoras de serviço não receberam como ameaça esta intervenção do governo municipal no mercado, embora alguns assinantes do serviço municipal tenham cancelado seus planos particulares.

De um modo geral, percebeu-se que a internet gratuita não domina o mercado da cidade, mas que as empresas privadas criaram planos alternativos e mais baratos, o que caracterizou uma intervenção positiva (COELHO, 2009).

O sinal de internet conta com um link de fibra ótica da Copel e é dividido entre o prédio da prefeitura, onde fica localizado o servidor, estabelecimentos de ensino, unidades de saúde, autarquias municipais e os assinantes do serviço. Por meio de uma torre central mais outras 5 (cinco) torres repetidoras espalhadas pelo município e nos Distritos o alcance de sinal 
é de $7 \mathrm{~km}$. Se colocadas em locais estratégicos conseguem atingir um raio de até $30 \mathrm{~km}$ de cobertura, o que propicia que os Distritos de Sertãozinho, Figueira do Oeste, Ivailândia, Sussui e Mandijuba também se beneficiem da internet gratuita.

O serviço é oferecido gratuitamente e o único custo que os usuários têm, sejam pessoas físicas ou jurídicas, é com a aquisição e instalação dos equipamentos. A prefeitura certificava em Engenheiro Beltrão, em 2018, sete lojas que participaram de treinamento, quanto às condições ideais e os equipamentos recomendados para os clientes para garantir, assim, a qualidade do serviço.

Nas tratativas de pesquisa, Engenheiro Beltrão não relatou dificuldades na implantação do projeto de cidade digital por meio do orçamento participativo, assim como não revelou reclamações por parte dos cidadãos, seja com o método de oferecimento do sinal de internet seja da qualidade, dos critérios para concessão do benefício ou problemas de qualquer outra ordem. Ressalta-se que essas informações, assim como as facilidades ou dificuldades de acesso, sob o ponto de vista dos cidadãos, não foram objetos de investigação desta pesquisa.

Um ponto negativo relatado foi quanto ao elevado índice de roubo de antenas de sinal de internet no ano de 2018, porém, embora não informado qual seria esse número, obteve-se que o fato das antenas possuírem rastreador conectado ao provedor municipal são facilmente localizadas e os criminosos presos em flagrante por roubo ou receptação, podendo pagar fiança no valor que varia de $\mathrm{R} \$ 1.000,00$ a $\mathrm{R} \$ 10.000,00$. A prefeitura passou a orientar a população para que só compre antenas de lojas especializadas, com nota fiscal, e que duvidem de produtos de origem e valores duvidosos.

Uma vez que o orçamento participativo é aquele que conta com o envolvimento daqueles que habitam as cidades na definição e decisão dos gastos públicos, apenas divulgar o projeto de cidade digital e pedir que a população opinasse por meio do preenchimento de campo específico no próprio carnê de IPTU, quanto ao que considerava ser prioridade de investimento para o próximo exercício financeiro pode se demonstrar frágil do ponto de vista de uma política pública de fato, pois embora tenha se demonstrado uma prática nos anos seguintes, não foi representativa como em 2009.

Cabe ainda revelar a dificuldade de contato e de informações mais detalhadas com as áreas responsáveis na prefeitura de Engenheiro Beltrão, uma vez que não houve retorno de tentativas de pedidos de informações via telefone e e-mail, apenas a devolutiva, via $e$-SIC, mais de 70 dias após o pedido, contrariando os prazos legais previstos na da Lei de Acesso à Informação (LAI), sob $\mathrm{n}^{\circ}$ 15.527/2011. A demora de resposta foi justificada pelo Departamento de Tecnologia da Informação como sendo resultado de manutenção e atualização do website da prefeitura municipal.

Constatou-se também que a prefeitura disponibiliza serviços públicos eletrônicos, o que contribui para o reconhecimento de uma cidade digital. Ela possui em seu portal web links de Ouvidoria, Fale Conosco, e-Sic, Portal da Transparência e acesso a serviços municipais tais como: emissão e impressão de guias de tributos, certidões negativas de imóvel e de contribuinte, entre outros. Solicitações de outros serviços públicos e pedidos de informações podem ser registradas e acompanhadas, via protocolo de atendimento, conforme determinação a LAI.

Ao se questionar se a prefeitura conhecia e tinha projetos para uma cidade digital, inseridos em seu plano de tecnologia da informação, e se estes projetos estavam alinhados a um planejamento estratégico, Engenheiro Beltrão demonstrou que não tem um planejamento estratégico público municipal. Ainda quando questionada a respeito de ser considerada uma cidade que planeja todo o seu orçamento ouvindo os interesses da população, constatou-se que apenas envolve seus cidadãos na aplicação dos recursos advindos, exclusivamente, do IPTU, mas que 2009 foi o único ano em que houve, de fato, um aumento exponencial na 
arrecadação do imposto, o que permite afirmar que o projeto para tornar a cidade digital atingiu seu objetivo, pois disponibilizar a internet gratuita no município é uma realidade possibilitada pelo IPTU participativo.

\section{CONCLUSÃO}

A tecnologia da informação, que envolve todos os recursos computacionais de processamento, transmissão e armazenagem de dados, criou condições para o surgimento da sociedade do conhecimento e a internet abriu uma infinidade de possibilidades de interação e de participação entre governos, cidadãos e sociedade. Na era da internet, a gestão pública se obriga a utilizar dos recursos da tecnologia da informação para os sistemas de disponibilização de informações e de serviços públicos, os quais contribuem para a criação de cidades consideradas digitais.

Verificou-se que Engenheiro Beltrão inclui digitalmente os cidadãos ao disponibilizar a internet gratuita, além de cumprir à legislação em se tratando de transparência pública ao disponibilizar alguns serviços públicos e informações municipais eletronicamente, tais como os dados orçamentário-financeiros. E que, ao incluir a população no processo decisório do orçamento público, mesmo que no simples ato de preenchimento de um campo no carnê do IPTU quanto ao que considera prioridade de investimento, demonstrou que é possível a participação popular para aumentar o potencial arrecadador do município e ainda permitir que os recursos sejam aplicados de acordo com a necessidade e vontade dos cidadãos.

Portanto, o objetivo da pesquisa foi alcançado, uma vez que Engenheiro Beltrão disponibiliza internet aos cidadãos sem custos e diretamente nas residências ou ainda, nas empresas da cidade, e por meio do aumento de arrecadação do IPTU e vontade popular quanto à destinação desse recurso, requisitos estes que acabaram por colaborar para que fosse considerada como uma cidade digital.

Os resultados auferidos demonstram que disponibilizar internet, e de maneira gratuita, aos cidadãos, sejam eles pessoas físicas ou jurídicas, após participação popular, e por meio de um imposto, o IPTU, contribuiu não só para o reconhecimento da cidade como digital, além disso, garantiu que a saúde e a educação andem juntas com o projeto, visto que para as famílias com filhos é preciso que estes estejam matriculados e frequentando a escola e com a carteira de vacinação atualizada. Assim sendo, é possível afirmar que o projeto de cidade digital é também de inclusão social e econômica dos cidadãos beltranenses, visto que a população passou a fazer parte das definições das prioridades de investimento do município, inclusive nos anos seguintes, as quais não são objeto desta pesquisa, visto que o destaque na arrecadação tenha se dado apenas em 2009, o que se credita ao projeto EBOnline.

As contribuições da pesquisa servem de exemplo para que a gestão pública aperfeiçoe suas práticas de gestão e inclua nas suas estratégias e serviços públicos oferecidos um projeto mais amplo de aproximação dos munícipes se utilizando da tecnologia da informação e da participação popular. Para outros municípios, destaca-se a possibilidade de inclusão e condução de projetos de cidade digital e orçamento participativo em suas estratégias e práticas de gestão.

Quanto às limitações da pesquisa, por se tratar de um caso único de resultado de amostra, esta é pequena devido ao universo de mais de cinco mil cidades brasileiras, porém a metodologia da pesquisa pode ser seguida em qualquer cidade que venha a ser analisada. Ainda, os dados apresentados são baseados na disponibilidade das informações no portal eletrônico da prefeitura no momento da coleta.

Por fim, conclui-se que a participação popular, como um método inovador de se fazer a gestão urbana, pode ser uma realidade desde que se desenhem estratégias capazes de aumentar e incentivar a participação social, assim como propiciar o atendimento ao anseio 
daqueles que habitam as cidades, contribuindo com a melhoria da qualidade de vida dos cidadãos, como foi o caso do projeto de cidade digital de Engenheiro Beltrão.

\section{Agradecimento}

CNPq - Bolsa de Produtividade em Pesquisa 


\section{REFERÊNCIAS}

AGUIAR, R. P. Municipalização da Internet em Engenheiro Beltrão. Trabalho de Conclusão de Curso. Especialização em Gestão Pública. Programa Nacional de Formação em Gestão Pública. Universidade Estadual de Maringá (UEM), 2011.

ALESINA, A.; ROSENTHAL, H. Partisan politics, divided government, and the economy. Cambridge University Press, 1995.

AVRITZER, L. Democracy and the public space in Latin America. Princeton: Princeton University Press, 2002.

AVRITZER, L. Modelos de deliberação democrática: uma análise do orçamento participativo no Brasil. In: SANTOS, Boaventura de S. (Org.). Democratizar a democracia: os caminhos da democracia participativa. Rio de Janeiro: Civilização Brasileira, p. 561-597, 2009a.

AZEVEDO, M. D. L. P. D. Cidade digital e as novas espacialidades urbanas: o caso de Piraí - RJ, 2012.

BESSELAAR (VAN DEN); P., MELIS, I; BECKERS, D. Digital Cities: Organization, Content, and Use. In T. ISHIDA \& K. ISBISTER (Eds.), Digital cities: Technologies, experiences, and future perspectives. Lecture Notes in Computer Science (vol. 1765), Berlin: Springer-Verlag, 18-32, 2000.

CASTELLS, M. A sociedade em rede. São Paulo: Paz e terra, 2005.

CASTLES, F. G.; OBINGER, H. Social expenditure and the politics of redistribution. Journal of European Social Policy, 17(3), 206-222, 2007.

COELHO, R. C. Estado, governo e mercado. Florianópolis: Departamento de Ciências da Administração/UFSC; [Brasília]: CAPES: UAB, 2009.

DALLARI, D. A. In: Estatuto da Cidade: Comentários a Lei Federal 10.257/2001. Coords. Dallari, A. A., Ferraz, S. 3 ed. São Paulo: Malheiros, 2010.

DOWNS, A. An economic theory of democracy, 1957.

ENGENHEIRO BELTRÃO. Prefeitura Municipal de Engenheiro Beltrão. EBonline e Cidade Digital, 2018.

FARIA, J. B. S. O gerencialismo no poder público municipal: o caso da reforma administrativa na empresa de urbanização do Recife. Dissertação (Mestrado em Administração Pública). Fundação Getulio Vargas/FGV. Escola Brasileira de Administração Pública e de Empresas/EBAPE. Rio de Janeiro, 2010.

FEDOZZI, L. Observando o orçamento participativo de Porto Alegre: análise histórica de dados, perfil social e associativismo. Porto Alegre: Tomo Editorial, 2007.

FERREIRA, M. D. A. Progressividade Fiscal no IPTU e o Princípio da Capacidade Contributiva. Revista da Procuradoria-Geral do Município de Porto Alegre, v. 17, 2003. 
FNP. Frente Nacional dos Prefeitos. A baixa arrecadação do IPTU nos municípios brasileiros, 2013.

GIL, A. C. Como elaborar projetos de pesquisa. 5. ed. São Paulo: Atlas, 2010.

GIL, A. C. Métodos e técnicas de pesquisa social. $7^{\text {a }}$ ed. São Paulo, SP: Atlas, 2019.

GOMES, L. P. Texto publicado no Informativo Mensal do CRA/CE. CRA em Ação, Ano 1, nº7. Ceará, 2005.

GUEDES, J. R. D. M. Comentários à lei de responsabilidade fiscal, 2001.

GUERREIRO, E. P. Cidade digital: infoinclusão social e tecnologia em rede. São Paulo: Senac São Paulo. 351p, 2006.

HIBBS, D. A. JR. Political parties and macroeconomic policy. American Political Science Review, 71(4), 1467-1487, 1977.

KHAIR, A. A. Gestão fiscal responsável simples municipal: guia de orientação para prefeituras. Brasília: Ministério do Planejamento, Orçamento e Gestão; BNDES, 2001.

IBGE. Instituto Brasileiro de Geografia e Estatística. Censo demográfico, 2010; 2018.

LAKATOS, E. M.; MARCONI, M. A. Fundamentos de metodologia científica. 8 ed. São Paulo: Atlas, 2017.

LARCINESE, V. Does political knowledge increase turnout? Evidence from the 1997 British general election. Public Choice, 131(3-4), 387-411, 2007.

LASMAR, E. M. Geoprocessamento aplicado ao cálculo de IPTU. Centro Federal de Educação Tecnológica de Minas Gerais. Campus Varginha-MG. Curso Técnico em Edificações. Relatório de Conclusão de Estágio, 2012.

LEMOS, A. Cibercultura, cultura e identidade. Em direção a uma "Cultura Copyleft". Contemporânea, v. 2, n. 2, 2004.

LÉVY, P.; LEMOS, A. Ciberdemocracia. Tradução de Alexandre Emílio. Lisboa: Instituto Piaget, 2002.

LIMA, F. C. M.; FERNANDES, A. F. P. O IPTU como instrumento de arrecadação e política urbana. Faculdade de Direito Luciano Feijão (FLF), 2014.

MACEDO, S. V.; VALADARES, J. L. Disponibilização dos dados governamentais abertos pelos poderes executivos estaduais brasileiros. E\&G Economia e Gestão, Belo Horizonte, v. 20, n. 57, Set./Dez. 2020.

MACHADO, H. B. Curso de Direito Tributário. 30ª ed. São Paulo: Malheiros Editores Ltda, 2009. 
MINGHELLI, M. Orçamento participativo: uma leitura jurídico-política. Canoas: Ulbra, 2005.

MOREIRA, J. C. R. O paradigma das cidades inteligentes: as dimensões do espaço urbano, 2013/14. Faculdade de Arquitectura e Artes - FAA. Universidade Lusíada do Porto, 2014.

NUNES, D. P. R. Administração Pública e a Lei de Responsabilidade Fiscal. São Paulo: Atlas, 2002.

OLIVEIRA, R. F. Responsabilidade fiscal. 2 ed. rev. São Paulo: Ed. Revista dos Tribunais, 2002.

PAES, N. L.; BUGARIN, N. S. Parâmetros tributários da economia brasileira. Estudos Econômicos (São Paulo), 36(4), 699-720, 2006.

PIRES, V. A. Orçamento participativo: o que é, para que serve, como se faz. Barueri: Manole, 2001.

REZENDE, D. A. Planejamento de estratégias e informações municipais para cidade digital: guia para projetos em prefeituras e organizações públicas. São Paulo: Atlas, 2012.

REZENDE, D. A. Strategic digital city: concept and model. 15th International Conference on Information Systems \& Technology Management - CONTECSI - 2018; pp. 0090-0107.

REZENDE, D. A.; RIBEIRO, S. S. Análise das Estratégias, Informações, Serviços Públicos Municipais e Tecnologias da Informação e suas Relações com Projetos de Cidade Digital Estratégica nas Capitais da Região Centro-Oeste do Brasil. Revista Brasileira de Gestão e Desenvolvimento Regional, 14(3), 2018.

SANTOS, P. M.; BERNARDES, M. B.; ROVER, A. J. Teoria e prática de governo aberto: Lei de acesso à informação nos executivos municipais da Região Sul. Florianópolis: Funjab, 2012.

SCHMIDT, M. G. When parties matter: A review of the possibilities and limits of partisan influence on public policy. European Journal of Political Research, 30(2), 155-183, 1996.

SILVEIRA, S. A. Governo Eletrônico e Inclusão Digital. In: Hermanns, Klaus (org). Governo Eletrônico - Os Desafios da Participação Cidadã. Fortaleza: Fundação Konrad Adenauer, p. 69-81, 2002.

SOUZA, L. V. S. et al. Aprendizado político no Conselho do Orçamento Participativo em Cachoeiro de Itapemirim-Espírito Santo-Brasil. Cadernos Gestão Pública e Cidadania, v. 24, n. 79, 2019.

SOUZA, M. L. Participação popular no planejamento urbano e na gestão orçamentária municipal no Brasil: um balanço e algumas questões. In: Fundação Konrad Adenauer. Participação cidadã: novos conceitos e metodologias. Fortaleza: Expressão Gráfica e Editora, p. 101-109, 2004. 
SUNDFELD, C. A. In: Estatuto da Cidade: Comentários a Lei Federal 10.257/2001. Coords. Dallari, Adilson Abreu; Ferraz, Sérgio. 3 ed. São Paulo: Malheiros, 2010.

TARAPANOFF, K. Inteligência social e inteligência competitiva. Revista Eletrônica de Biblioteconomia e Ciência da Informação. Número especial, 11-26, 2004.

TURBAN, E.; MEREDITH, J. R. Fundamentals of Management Science. Boston: Irwin, 1994.

VENÂNCIO, R. D. O. Como funciona o orçamento participativo? DiverCidade, 2012.

WITTMAN, D. A. The myth of democratic failure: why political institutions are efficient. University of Chicago Press, 1995.

YIN, R. K. Estudo de caso: planejamento e métodos. Porto Alegre: Bookman, 2015. 